Published in The Journal of the European Economic Association 5 (2007), 400-

410

\title{
Pricing of Scientific Journal and Market Power ${ }^{*}$
}

\author{
Mathias Dewatripont, ${ }^{\mathrm{a}}$ Victor Ginsburgh, ${ }^{\mathrm{b}}$ Patrick Legros ${ }^{\mathrm{c}}$ and \\ Alexis Walckiers ${ }^{\mathrm{d}}$
}

November 8, 2006

\begin{abstract}
We analyze the empirical relationship between journal prices, their quality measured by their citation counts, their age, as well as conduct of publishers. The database covers 22 scientific fields and over 2600 among the most highly reputed and cited journals in 2003. We show that (a) for-profit journals charge roughly 3 times more than journals run by scientific societies; (b) the number of citations has a positive impact on prices; (c) there are large differences in prices across fields that vary from 1 and 6; these are highly (and positively) correlated with the degree of concentration in the industry.
\end{abstract}

\footnotetext{
* This paper revisits Section 3 of Dewatripont et al. (2006), and extends the results showing that publishers' concentration in a scientific field has an impact on prices. We are grateful to Estelle Cantillon and Françoise Vandooren for comments on previous versions.

${ }^{a}$ ECARES, Université Libre de Bruxelles and CEPR.

${ }^{\mathrm{b}}$ ECARES, Université Libre de Bruxelles and CORE, Université catholique de Louvain.

${ }^{c}$ ECARES, Université Libre de Bruxelles and CEPR.

${ }^{\mathrm{d}}$ ECARES, Université Libre de Bruxelles.
} 


\section{Introduction}

The high prices of scientific journals, and the burden they represent for university library budgets, are a subject of intense debate in academic and policy circles. This paper offers systematic evidence on price levels and on their determinants. Though we have now entered the era of electronic journals and of bundled pricing, our analysis concentrates on prices of individual printed journals. Individual prices are still relevant, since pricing of bundles is very often based on the libraries' pre-existing print subscriptions, and individual electronic journals are usually priced as a percentage of their print price. ${ }^{1}$

Electronic publishing does represent some specific costs (as well as savings, in other dimensions), but it is important to stress that this transition cannot be held responsible for the high prices that libraries complain about. While expenses linked to electronic publishing have really started in the mid-1990's, ${ }^{2}$ data discussed by Tenopir and King (2000) show that very significant price increases have taken place much earlier. Kyrillidou and Young (2004, p. 11) indicate that the price for an average journal rose faster between 1986 and 1995 at a time where technology was stable, than between 1995 and 2003, where publishers have faced costs to undertake the electronic transition.

Many authors have provided evidence indicating that journals held by FP publishers are significantly more expensive than journals published by NFP organizations. However, these studies are either concentrated on specific fields ${ }^{3}$ or aggregate several fields. ${ }^{4}$ As will be clear later on, there are large differences across fields. Therefore the results obtained for one field may not be relevant for others and aggregating fields may give a biased view. This led us to study the prices charged in 2003 by 2,630 journals in 22 fields of natural and social sciences.

We estimate a simple hedonic model in which we isolate the effect of observable measures of quality (citations, number or articles per issue, age of the journal) and of conduct (for profit publisher, scientific society publisher, scientific society journal managed by a for profit publisher).

The paper uses the same database as Dewatripont et al. (2006), but the analysis has been extended and deals in a more direct way with the influence on

\footnotetext{
${ }^{1}$ Elsevier's senior Vice-President Karen Hunter suggest that even in the electronic age, individual journals remain as strong as ever: "I don't see the end of the individual journal." She also added that Elsevier had seen a return to demand for title-by-title subscription in place of all-you-can-eat deals. See Elsevier reviews its journal models, 2006. www.iwr.co.uk/information-worldreview/news/ 2154589/elsevier-reviews-journal-models. Accessed April 28, 2006

${ }^{2}$ As indicated for example by Elsevier. See Reed Elsevier (2005).

3 Economics in Chressanthis and Chressanthis (1994) and Bergstrom (2001) (extended by Bergstrom and Bergstrom, 2004 to 5 other fields), mathematics in Binman et al., 1997, agriculture and biology in Cornell, 1998, as well as a study by the University of Wisconsin-Madison, 1999).

${ }^{4}$ McCabe (2002), Tenopir and King (2000), Kyrillidou and Young (2004), White and Creaser (2004), SQW Ltd (2003).
} 
prices of the degree of concentration in the industry. This database is described in Section 2. Section 3 deals with the empirical relationship between journal prices, their quality measured by citations (or impact factor), age, number of articles per volume, their for-profit (FP), not-for-profit (NFP) or for profit on behalf of not for profit (NFPP) status, and fixed scientific field effects. We also introduce the degree of concentration of publishers (shares enjoyed by the single, and the two first publishers), which proves to have a very significant effect on prices. Section 4 concludes.

\section{Data}

The database covers 22 scientific fields and over 2600 among the most highly reputed and cited journals, selected in the following way:

- "fields" are defined by the Journal Citation Reports, 2003 (JCR in what follows)

- all fields with more than 135 journals were selected in science (11 fields) and all fields with more than 80 journals in the social sciences (6 fields). This selection criterion unfortunately excluded chemistry and physics, which are subdivided into quite small fields, with the consequence that no single field contains 135 journals. We therefore included five more fields, which did not match the 135-journals criterion in science, but were those with the largest number of journals in chemistry and physics. See Table 1 for the fields included. ${ }^{5}$

We classified these journals into three categories: (a) FP journals published by for-profit publishers, (b) NFP journals managed by not-for-profit publishers (scientific societies, University presses, etc.), and NFPP journals published and distributed by FP firms on account of scientific societies. ${ }^{6}$

SWETS provides a database that includes in particular the following information for approximately 130,000 journals: prices (domestic and foreign between 2001 and 2004), ${ }^{7}$ publisher, and (quite often) year of first publication.

\footnotetext{
${ }^{5}$ These fields are not mutually exclusive: The same journal can be classified in "Mathematics, applied" and in "Mathematics" for instance. However, less than ten percent appear in more than one field.

${ }^{6}$ To do this we used the Catalogo Italiano dei Periodici Acnp (acnp.cib.unibo.it/cgi$\mathrm{ser} / \mathrm{start} / \mathrm{it} / \mathrm{cnr} / \mathrm{fp} / \mathrm{html}$ ) and the web. Many journals can be classified easily into one category, but for some journals it is less obvious, and some discretion had to be used.

${ }^{7}$ There are eight entries for prices: Domestic and foreign, each for four years. These prices are expressed in various currencies (usually the currency of the country in which the publisher is located). We converted these prices into Euros using IMF exchange rates (World Economic Outlook, 2005). The evolution of prices cannot be used directly for at least two major reasons: (a) the Euro was introduced in 2001 and several prices are still expressed in national currencies in 2001, and even in 2002 (note that some publishers significantly increased their prices at that moment); and (b) the Euro has appreciated by some 40 percent against the dollar between July $2001(\$ 1=0.87$ Euro) and July $2004(\$ 1=1.21$ Euro), that is during the period under study, an effect that cannot be corrected for. This may be at the origin of a systematic bias that makes NFP
} 
The JCR (2003) provides the number of citations and impact factors. The two databases were merged. Though some journals in JCR are not in the SWETS database (some $8 \%$ percent), there is no systematic bias.

Since turnover per field is not available, we constructed three types of producer market shares to measure concentration: share in total citations, share in number of journals, share in prices (obtained by adding prices of individual journals, and dividing by the sum of the prices in a given field), assuming that a library would buy the whole bundle of most-cited journals, or would buy only part of these, but in proportion to total shares. This also roughly represents the shares of bundles in the so-called "big deal" arrangements. Concentration is measured in terms of the share enjoyed by the single $(\mathrm{C} 1)$, and the two largest (C2) firms.

Finally, we took into account the language in which the journal is published (English, All other), as well as the number of articles in each journal in its 2003 volume.

We were able to retrieve the full set of information for over 2,600 journals that are clearly representative of top journals which receive the largest number of citations. These are also the journals, which are widely read by scientists, even if they also publish in other journals.

In 2003, the most important publishers were Elsevier (involved in all 22 fields), Wiley, Kluwer and Taylor and Francis (21 fields), Springer (16 fields), Blackwell (14 fields), Lippincott (4 fields only, but very heavily in 2 fields). These are all FP firms some of which (Blackwell, in particular) manage NFP journals. Market shares of the two largest firms in each field can be found in Table $1 .^{8}$

\section{A Reduced-Form Econometric Analysis}

Are some observed characteristics and/or rules of conduct relevant in the pricing of scientific journals? We estimate a reduced form model in which (the log of) prices are regressed on observed quality characteristics, type of conduct and field dummies. Observed characteristics consist of (a) the field-normalized (log of the) number of citations (since we pool over fields, and since some fields have more citations than others, we normalize by dividing the number of citations to journal $i$ which belongs to field $j$ by the average number of citations of all journals belonging to the same field $j$ ), (b) the field-normalized (log of the) age (2003 minus year of first publication, normalized by field, since some

journals, mainly located in the United States, look cheaper than FP journals, more frequently located in Europe. However, this bias should not be large, since we averaged prices over the whole period, smoothing out the two extreme values. We eventually created a price indicator (called "prices" in what follows) that is the average of available prices.

${ }^{8}$ Note that in the meantime, Kluwer and Springer merged, and Cell Press was acquired by Elsevier. 
fields are older than others), (c) the language of the journal (English, all other), (d) the (log of the) number of articles in the 2003 volume, which may also represent cost factors (handling of papers, refereeing, etc.). Dummy variables describe conduct: some journals are run by for profit publishers (FP), some by not-for-profit publishers or scientific societies (NFP) and some NFP journals are published by FP companies (NFPP). Other dummies represent fields, which may be taken as proxies for unobserved quality or conduct characteristics. We allow for interaction terms between observed characteristics and conduct to check whether the relationship differs across types of conduct. We also run alternative specifications, with prices (and other variables) per article instead of per journal, as well as impact factors in 2003 rather than citations. A single equation is estimated pooling all the observations. Regression coefficients are common to all fields, only intercepts vary (fields are represented by dummy variables).

Conduct and citations may both be endogenous. Indeed, since mergers and acquisitions were quite frequent during the last 10 to 15 years, it may be that FP publishers acquired specific (that is expensive) NFP journals only, leaving the less profitable ones to scientific societies. One possibility to avoid this endogeneity would be to run the regressions with journals that did not change ownership during, say the last 20 years. We did however not pursue this issue: though ownership changed during the last years, most deals were struck between FP publishers only. To get rid, at least partly, of endogeneity between prices and citations, we also estimate a two-equations system in which citations are instrumented by lagged citations and age of the journal.

In Table 2, we show the results of four regressions. In Eqs. (1), (2), and (4), the dependent variable is the logged price per journal, while Eq. (3) deals with logged prices per article. In Eq. (2) current citations are instrumented by ten year-lagged citations, age and their interactions with conduct (FP, NFP, NFPP). In Eq. (4) they are replaced by current impact factors. Since the results are very similar, our comments concentrate on Eq. (1).

Most parameters ${ }^{9}$ are significantly different from zero at the less than one percent probability level. The only coefficients that are not are those carried by the interaction terms NFPP with Number of citations (or Impact factor), Age and Number of articles (this simply means that, in this dimension, NFPP journals are not different from NFP journals).

Firstly, FP and NFPP journals charge roughly 3 and 2 times more than NFP journals, as shown by the coefficients picked by the FP and NFPP dummies. This confirms earlier findings. ${ }^{10}$

\footnotetext{
${ }^{9}$ Other than the field dummies, for which an F-test rejects equality. Coefficients vary between 0.82 and +0.84 .

${ }^{10}$ Cornell (1998) finds similar results but he studies only agricultural and biological journals. Moreover he divides NFP into Universities, Societies and Government. White and Creaser (2004) find that Oxford and Cambridge University Presses set lower prices than most FP. Chressanthis
} 
Secondly, prices increase with number of citations (or impact factors) and decrease with age. The price elasticity of a one percent increase in (fieldnormalized) citations is positive: In Eq. (1) it is equal to 0.14 for NFP and NFPP journals, and to 0.25 (that is $0.14+0.11$ ) for FP journals. The effect is similar, though somewhat larger in Eqs. (2) and (3). The price elasticity of a one percent increase in age is negative (-0.14 to -0.35$)$ for NFP journals. Older NFP journals are cheaper than more recent ones, but others (NFPPs and FPs) shade the effect of age, which may be due to FP journals being born later than NFP journals. As a result, FP and NFPP journals put less weight on age than NFP journals, and take advantage to a larger extent of the number of citations that they receive.

The signs involving citations are particularly interesting. Indeed, they result from two effects. When a journal is cited, this is usually taken as an indication of "quality" and of high value to the reader. This can turn a profit-maximizing publisher to raise its price since the willingness to pay of readers increase. McCabe $(2002,2004)$ takes this approach when analyzing the behavior of FP publishers facing libraries, which try to buy the "best-value-for-money journals." However, on average, one should expect that more citations imply larger circulation, and therefore, lower average production costs. ${ }^{11}$ As for the influence of age on prices, there are also two effects that may go in opposite directions. Launching of a new journal generates sunk costs that have to be recovered. Tenopir and King (2000) estimate that accumulated profits of a new journal are negative during the first six years. The journal may thus charge a higher price when it is new. On the other hand, the publisher may use an introductory price strategy: low price first to attract new readers and then increase prices once the journal is mature.

Thirdly, the number of articles plays an important role, with a price elasticity of 0.26 to 0.45 : Increasing the number of articles by 10 percent increases the price of a journal by 3 to 5 percent. There are no differences between FP, NFP and NFPP journals.

and Chressanthis (1994) find that being published by an NFP very significantly reduces the subscription price of an economic journal. Bergstrom and Bergstrom (2004) report that a page published by a FP is between 3 and 5 times more expensive than a page published by a NFP in ecology, economics, atmospheric sciences, mathematics neuroscience and physics. See also Bergstrom (2001).

11 This assumption is vigourously disputed by publishers. The only data at hand are those collected by Bergstrom (www.econ.ucsb.edu/\%7Etedb/Journals/pricing.html) on 103 journals. A linear correlation between citations and circulation leads to $\mathrm{r}=+0.748$, though $A E R, J P E$ and Econometrica may be considered as outliers. Without $A E R$, the correlation is still equal to +0.622 , and discarding $A E R, J P E$ and Econometrica leads to $\mathrm{r}=+0.590$. All three coefficients are largely different from zero at the 0.01 probabilty level. To avoid the influence of outliers, we also worked with ranks (both for citations and circulation). The resulting Spearman rank correlation coefficient is equal to +0.538 ; its t-value (the usual test, see Spiegel, 1956) is equal to 6.41 with 101 degrees of freedom which shows the $r$ value to be significantly different from 0 at a smaller than 0.001 probability level. If circulation data were available, one could envisage estimating a more complete model. 
Fourthly, English-speaking journals are 20 to 60 percent more expensive than journals in other languages.

Finally, there are large differences in prices across fields that remain unexplained. The "cheapest" field is Law, the "most expensive" ones are Physics and Chemistry. According to Eq. (1), "Law", "Physics, applied" and "Chemistry, physical" charge respectively 43, 230 and 245, while Economics charges 100 . Average prices vary thus between 1 and 6 . To analyze the reasons, we first introduced 42 (2 times 21) interaction terms between FP and fields and NFPP and fields in Eq. (1). A standard F-test shows that this significantly reduces the residual variance of the regression $\left(\mathrm{F}_{42}, 2576=2.54\right)$, so that the differences seem clearly related to conduct in the industry.

We calculated Spearman rank correlation coefficients (See Siegel, 1956) between the coefficients picked by field dummies and degree of concentration of publishers, that is the share per field enjoyed by the first $(\mathrm{C} 1)$ and the two first (C2) firms. The coefficients appear in the first two lines of Table 3. All of them are positive and significantly different from zero as shown by the t-values that are given next to the coefficients. Larger prices are thus correlated with larger concentration ratios.

Though there may be some concern that concentration could be endogenous, we re-estimated our basic equation, removing the fixed effect field dummies, replacing them by concentration shares of publishers per field. ${ }^{12}$ Results are given in the lower part of Table 3. Though the R-squared are smaller than in the specifications with fixed effects, the results are qualitatively similar to those of Table 2, and the effect of the concentration variables is again positive and significantly different from 0 . We also interacted conduct (here NFP) with concentration shares (This could not be done for concentration in prices, since there is only one NFP firm (IEEE), which is first in Engineering, electric and electronic, and which ties with an FP firm (Elsevier)). For concentration in citations and number of journals, NFPs shade somewhat their power compared to FPs.

All results point thus in the same direction. Concentration (in terms of prices, number of citations and number of journals) is correlated with the average price of journals. Clearly these results should be confirmed by larger samples of journals, that is larger number of fields, and more sophisticated estimation methods to avoid possible endogeneity problems (in particular when concentration in prices is used), but given the precision of our estimates, it is doubtful that the results could be reversed.

\section{Conclusions}

Our empirical investigation documents a certain number of facts:

\footnotetext{
${ }^{12}$ The concentration shares are thus equal for all the journals belonging to a specific field.
} 
1. There exist large price differences across fields.

2. These differences seem to be correlated with the market power of publishers. The larger the concentration ratio, the larger the average price in a field, price to which should be added the large difference between FPs, NFPPs and NFPs.

3. As a general rule, FP journals charge four times as much on average than NFP journals, for given number of citations, age, language, number of articles and field (or concentration ratio). Journals of scientific societies managed by FP publishers (NFPP) are twice as expensive as NFP journals (scientific societies exercise some control on prices).

4. Prices are positively correlated with quality measured by the number of citations they receive (even when citations are instrumented), and this effect is larger for FP journals.

We take the first finding as indicative of the fact that substitution possibilities across journals are limited, allowing for a significant amount of discretion in the setting of journal prices. Indeed, the technology of producing journals is widely available across fields of study, and the financial rewards offered to scientists as authors, referees and editors is sufficiently limited that differences in their labor market opportunities should not translate into very significant journal production costs across disciplines. Our finding is therefore indicative of large differences in price-cost ratios across disciplines, which is confirmed by the second finding that market concentration increases average prices.

Our third and fourth findings are consistent with the first two. We confirm earlier research concerning the large price difference between FP and NFP journals, and show that prices of NFPP journals are somewhere in between. Moreover, we show that prices increase with citation counts while we have argued that costs should tend to fall when citation counts rise. This is consistent with "value-based pricing" (à la McCabe, 2002, 2004) rather than with costbased pricing, and is again indicative of publishers' ability to exercise discretion in price setting, since journals and papers are hardly substitutes, and researchers need all of them.

Note that these findings do not invalidate the fact that, as stressed for example by Tenopir and King (2000), on average, FP journals may have higher costs than some learned societies because they have lower average circulations. But our evidence (conclusion 4) indicates that individual journal prices do seem to follow other factors than costs. Pricing is consistent with the idea that successful journals are priced higher so as to get a return on previous investment, and in particular to recoup the initial investment in new journals. Unsurprisingly, this feature especially characterizes FP journals. On the other hand, FP publishers have given new impetus to scientific publishing. They 
launched many new field journals, while NFP publishers have focused on high quality journals. ${ }^{13}$

\section{References}

Bergstrom, Ted (2001), Free labor for costly journals, Journal of Economic Perspectives 15, 183-198.

Bergstrom, Carl and Ted Bergstrom (2004), The costs and benefits of library site licenses to academic journals, Proceedings of the National Academy of Sciences of the USA 101, 897-902.

Binman, Joan, Rob Kirby and Krzystzof Apr (1997), Comparative prices of maths journals, mimeo, Berkeley.

Chressanthis, George and June Chressanthis (1994), The determinants of library subscription prices of the top-ranked economic journals: An econometric analysis, Journal of Economic Education 25, 367-382.

Cornell (1998), Journal price study of core agricultural and biological journals, Cornell University.

Dewatripont, Mathias, Victor Ginsburgh, Patrick Legros, Alexis Walckiers, Jean-Pierre Devroey, Marianne Dujardin, Françoise Vandooren, Pierre Dubois, Jérôme Foncel, Marc Ivaldi, Marie-Dominique Heusse (2006), Study on the economic and technical evolution of the scientific publication markets in Europe, Brussels: European Commission.

Kyrillidou, Martha and Mark Young (2004), ARL statistics 2002-2003, Washington D.C.: Association of Research Libraries.

Mabe, Michael and Mayur Amin (2001), Growth dynamics of scholarly and scientific journals, Scientometrics 51, 147-162.

McCabe, Mark (2002), Journal pricing and mergers: A portfolio approach, American Economic Review 92, 259-269.

McCabe, Mark (2004), Information goods and endogenous pricing strategies: The case of academic journals, Economics Bulletin 12, 1-11.

Reed Elsevier (2005), Submission to DG Research study on scientific markets in Europe, mimeo.

\footnotetext{
${ }^{13}$ See Tenopir and King, 2000, Mabe and Amin, 2001. Note that there is heterogeneity within categories. This is visible when we compare the different fields. Online journal creation has been embraced by some scientific societies but not so much by others. For instance, the American Economic Association has only three journals, both available in print and digital formats, the American Psychological Society has 49 journals; the engineers' society IEEE has 126 journals, and sells bundles, both in print format or online, the Society for Industrial and Applied Mathematics (SIAM) has 13 online journals, the American Chemical Society has 33 journals in the ISI-JCR and houses abstracting and indexing collections (the Chemical Abstracts Service) while the American Medical Association seems to have only one, the celebrated JAMA, but also has JAMA \& Archives for a very large number of sub fields, though it is not clear whether these are all separate journals. The Econometric Society which launched Econometrica in 1933 never launched another journal. It just decided to start two new electronic journals.
} 
Spiegel, Sidney (1956), Nonparametric Statistics for the Behavioral Sciences, New York: McGraw-Hill.

SQW Ltd (2003), Economic analysis of scientific research publishing, Cambridgeshire: The Wellcome Trust.

Tenopir, Carol, and Donald King (2000), Towards Electronic Journals, Washington, D.C.: SLA Publishing.

University of Wisconsin, Madison (1999), Measuring journal cost-effectiveness: Ten years after Barschall (http://www.library.wisc.edu/projects/glsdo/cost.html)

White, Sonya and Claire Creaser (2004), Scholarly journal prices: Selected trends and comparisons, LISU Occasional Papers no 34. 
Table 1 Shares of the Two Largest Firms (Breakdown by Fields)

\begin{tabular}{|c|c|c|c|c|c|c|c|c|c|c|c|c|}
\hline & \multicolumn{4}{|c|}{ No. of citations } & \multicolumn{4}{|c|}{ No. of journals } & \multicolumn{4}{|c|}{ Prices of bundles } \\
\hline & \multicolumn{2}{|c|}{ First firm } & \multicolumn{2}{|c|}{ Second firm } & \multicolumn{2}{|c|}{ First firm } & \multicolumn{2}{|c|}{ Second firm } & \multicolumn{2}{|c|}{ First firm } & \multicolumn{2}{|c|}{ Second firm } \\
\hline & Name & Share & Name & Share & Name & Share & Name & Share & Name & Share & Name & Share \\
\hline Biochemistry anf molecular biology & $\mathrm{E}$ & 23 & ASS & 21 & $\mathrm{E}$ & 29 & W & 8 & $\mathrm{E}$ & 43 & W & 10 \\
\hline Cell biology & Nature & 20 & Cell Pr. & 18 & $\mathrm{E}$ & 18 & $\mathrm{Bl}$ & 9 & $\mathrm{E}$ & 14 & $\mathrm{~W}$ & 7 \\
\hline Chemical, multidisciplinary & ASS & 49 & W & 18 & ASS, W & 11 & & & $\mathrm{~K}, \mathrm{~W}$ & 19 & & \\
\hline Chemistry, physical & $\mathrm{E}$ & 56 & ASS & 22 & $\mathrm{E}$ & 38 & $\mathrm{~K}$ & 14 & $\mathrm{E}$ & 60 & $\mathrm{~K}$ & 15 \\
\hline Clinical neurology & Lip & 32 & E & 14 & $\mathrm{E}$ & 16 & $\mathrm{~L}$ & 13 & E & 23 & $\mathrm{Sp}$ & 20 \\
\hline Economics & E & 29 & $\mathrm{Bl}$ & 21 & $\mathrm{E}$ & 27 & $\mathrm{Bl}$ & 19 & $\mathrm{E}$ & 51 & $\mathrm{~K}$ & 12 \\
\hline Education and educational research & $\mathrm{T} \& \mathrm{~F}$ & 12 & ASS & 11 & $\mathrm{~T} \& \mathrm{~F}$ & 19 & $\mathrm{Bl}$ & 10 & $\mathrm{~T} \& \mathrm{~F}$ & 32 & E & 13 \\
\hline Engineering, chemical & E & 57 & W & 14 & E & 30 & $\mathrm{~T} \& \mathrm{~F}$ & 12 & E & 54 & $\mathrm{~K}$ & 12 \\
\hline Engineering, electric and electronic & IEEE & 72 & E & 11 & IEEE & 40 & $\mathrm{E}$ & 15 & E, IEEE & 24 & & \\
\hline Law & $\mathrm{Ch}, \mathrm{H}$ & 10 & & & Harv & 6 & Am Bar & 5 & $\mathrm{~K}$ & 16 & $\mathrm{E}$ & 11 \\
\hline Materials sciences, multidisciplinary & $\mathrm{E}$ & 49 & ASS & 8 & $\mathrm{E}$ & 27 & $\mathrm{~K}$ & 7 & $\mathrm{E}$ & 52 & $\mathrm{~K}$ & 11 \\
\hline Mathematics, applied & E & 37 & SIAM & 16 & $\mathrm{E}$ & 27 & $\mathrm{Sp}$ & 7 & $\mathrm{E}$ & 39 & W & 15 \\
\hline Mathematics & $\mathrm{E}$ & 23 & $\mathrm{Sp}$ & 17 & $\mathrm{E}, \mathrm{Sp}$ & 15 & $\mathrm{~K}$ & 10 & $\mathrm{E}$ & 34 & $\mathrm{Sp}$ & 15 \\
\hline Neuroscience & $\mathrm{E}$ & 35 & W & 11 & $\mathrm{E}$ & 31 & $\mathrm{Bl}$ & 7 & $\mathrm{E}$ & 40 & W & 17 \\
\hline Pharmacy & $\mathrm{E}$ & 29 & ASS & 12 & $\mathrm{E}$ & 20 & $\mathrm{~T} \& \mathrm{~F}$ & 9 & $\mathrm{E}$ & 37 & W & 11 \\
\hline Physics, applied & ASS & 54 & $\mathrm{E}$ & 14 & $\mathrm{E}$ & 21 & ASS & 11 & $\mathrm{E}$ & 35 & ASS & 15 \\
\hline Physics, multidisciplinary & ASS & 58 & $\mathrm{E}$ & 24 & ASS, E & 16 & & & $\mathrm{E}$ & 43 & ASS & 15 \\
\hline Plant science & ASS & 16 & $\mathrm{Bl}$ & 15 & $\mathrm{~K}$ & 11 & $\mathrm{Bl}, \mathrm{Sp}$ & 8 & $\mathrm{~K}$ & 24 & $\mathrm{Sp}$ & 16 \\
\hline Psychology, clinical & ASS & 30 & E,PhPP & 11 & $\mathrm{~K}$ & 15 & ASS & 13 & $\mathrm{~K}$ & 21 & $\mathrm{E}$ & 19 \\
\hline Psychology, multidisciplinary & ASS & 48 & $\mathrm{Bl}, \mathrm{E}, \mathrm{L}$ & 5 & $\mathrm{~T} \& \mathrm{~F}$ & 13 & ASS & 10 & $\mathrm{E}$ & 19 & $\mathrm{~T} \& \mathrm{~F}$ & 18 \\
\hline Sociology & ASS & 15 & $\mathrm{Bl}$ & 14 & Sage & 17 & $\mathrm{Bl}$ & 15 & Sage & 24 & $\mathrm{~T} \& \mathrm{~F}$ & 17 \\
\hline Surgery & $\mathrm{L}$ & 26 & Saund & 15 & $\mathrm{Sp}$ & 16 & $\mathrm{E}$ & 13 & $\mathrm{Sp}$ & 22 & $\mathrm{E}$ & 14 \\
\hline \multicolumn{13}{|l|}{ Total no. of cases } \\
\hline Blackwell & & 0 & & 4 & & 0 & & 6 & & 0 & & 0 \\
\hline Elsevier & & 9 & & 6 & & 13 & & 2 & & 15 & & 4 \\
\hline Kluwer or Springer & & 0 & & 1 & & 4 & & 4 & & 5 & & 7 \\
\hline NFP & & 10 & & 7 & & 4 & & 4 & & 1 & & 2 \\
\hline Wiley & & 0 & & 3 & & 1 & & 1 & & 1 & & 5 \\
\hline
\end{tabular}

Am Bar = Americ. Bar Assoc.; ASS= Americ. Scientific Assoc.; Bl = Blackwell; Cell Pr = Cell Press; Ch = Chicago; E = Elsevier;

IEEE = IEEE; H = Harvard; K = Kluwer; L = Lippincott; Nature = Nature; PhPP = Physicians Postgrad. Press; Saund = Saunders;

SIAM = SIAM; $\mathrm{Sp}=$ Springer $; \& \mathrm{~F}=$ Taylor $\&$ Francis $; \mathrm{W}=$ Wiley .

In case of ties of two or more firms, all are counted in the total number of cases; if two firms are tying as first, no "second" firm is listed. 
Table 2 Regression Results

\begin{tabular}{|c|c|c|c|c|c|c|c|c|}
\hline & \multicolumn{2}{|c|}{ Equation (1) } & \multicolumn{2}{|c|}{ Equation (2) } & \multicolumn{2}{|c|}{ Equation (3) } & \multicolumn{2}{|c|}{ Equation (4) } \\
\hline & Coeff. & St. Err. & Coeff. & St. Err. & Coeff. & St. Err. & Coeff. & St. Err. \\
\hline For profit dummy (FP) & 1.494 & 0.158 & 1.602 & 0.184 & 1.271 & 0.044 & 1.079 & 0.136 \\
\hline FP for NFP account (NFPP) & 0.705 & 0.200 & 0.858 & 0.235 & 0.708 & 0.053 & 0.573 & 0.179 \\
\hline No. of citations & 0.139 & 0.020 & 0.156 & 0.027 & 0.194 & 0.027 & & \\
\hline No. of citations*FP & 0.107 & 0.025 & 0.167 & 0.036 & 0.074 & 0.035 & & \\
\hline No. of citations*NFPP & 0.024 & 0.030 & 0.061 & 0.040 & -0.051 & 0.041 & & \\
\hline Age & -0.215 & 0.035 & & & -0.346 & 0.042 & -0.142 & 0.034 \\
\hline Age*FP & 0.277 & 0.046 & & & 0.261 & 0.055 & 0.360 & 0.046 \\
\hline Age*NFPP & 0.114 & 0.055 & & & 0.103 & 0.066 & 0.139 & 0.055 \\
\hline No. of articles & 0.321 & 0.028 & 0.268 & 0.033 & & & 0.431 & 0.025 \\
\hline No. of articles*FP & -0.049 & 0.033 & -0.053 & 0.039 & & & 0.027 & 0.030 \\
\hline No. of articles*NFPP & 0.011 & 0.043 & -0.003 & 0.050 & & & 0.036 & 0.040 \\
\hline Impact factor & & & & & & & 0.165 & 0.027 \\
\hline Impact factor*FP & & & & & & & 0.004 & 0.034 \\
\hline Impact factor*NFPP & & & & & & & 0.004 & 0.043 \\
\hline English language dummy & 0.421 & 0.053 & 0.370 & 0.061 & 0.167 & 0.063 & 0.493 & 0.053 \\
\hline Intercept & 3.590 & 0.142 & 3.772 & 0.162 & 1.405 & 0.093 & 3.134 & 0.125 \\
\hline \multicolumn{9}{|l|}{ Field dummies } \\
\hline Biochemistry anf molecular biology & 0.618 & 0.075 & 0.701 & 0.085 & -0.271 & 0.086 & 0.337 & 0.074 \\
\hline Cell biology & 0.563 & 0.081 & 0.680 & 0.091 & -0.132 & 0.095 & 0.377 & 0.081 \\
\hline Chemical, multidisciplinary & 0.378 & 0.091 & 0.486 & 0.106 & -0.590 & 0.104 & 0.103 & 0.090 \\
\hline Chemistry, physical & 0.961 & 0.093 & 1.047 & 0.104 & 0.097 & 0.109 & 0.762 & 0.094 \\
\hline Clinical neurology & 0.026 & 0.083 & 0.098 & 0.095 & -0.698 & 0.098 & -0.156 & 0.084 \\
\hline Economics & 0.000 & - & 0.000 & - & 0.000 & - & 0.000 & - \\
\hline Education and educational research & -0.171 & 0.091 & -0.246 & 0.097 & -0.015 & 0.110 & -0.113 & 0.093 \\
\hline Engineering, chemical & 0.374 & 0.088 & 0.437 & 0.096 & -0.339 & 0.104 & 0.199 & 0.089 \\
\hline Engineering, electric and electronic & 0.497 & 0.078 & 0.649 & 0.086 & -0.213 & 0.090 & 0.280 & 0.078 \\
\hline Law & -0.821 & 0.089 & -0.827 & 0.094 & -0.531 & 0.105 & -0.783 & 0.091 \\
\hline Materials sciences, multidisciplinary & 0.558 & 0.080 & 0.738 & 0.096 & -0.246 & 0.093 & 0.355 & 0.081 \\
\hline Mathematics, applied & 0.586 & 0.078 & 0.665 & 0.087 & 0.199 & 0.093 & 0.505 & 0.079 \\
\hline Mathematics & 0.334 & 0.076 & 0.388 & 0.084 & 0.036 & 0.092 & 0.298 & 0.078 \\
\hline Neuroscience & 0.443 & 0.075 & 0.586 & 0.084 & -0.212 & 0.089 & 0.273 & 0.076 \\
\hline Pharmacy & 0.356 & 0.076 & 0.356 & 0.085 & -0.336 & 0.090 & 0.213 & 0.077 \\
\hline Physics, applied & 0.845 & 0.103 & 1.033 & 0.116 & -0.460 & 0.116 & 0.476 & 0.102 \\
\hline Physics, multidisciplinary & 0.888 & 0.108 & 1.047 & 0.119 & -0.089 & 0.125 & 0.629 & 0.108 \\
\hline Plant science & 0.232 & 0.082 & 0.294 & 0.088 & -0.351 & 0.098 & 0.149 & 0.084 \\
\hline Psychology, clinical & -0.103 & 0.092 & -0.081 & 0.100 & -0.233 & 0.112 & -0.150 & 0.095 \\
\hline Psychology, multidisciplinary & -0.086 & 0.088 & -0.074 & 0.091 & -0.053 & 0.106 & -0.058 & 0.090 \\
\hline Sociology & -0.235 & 0.092 & -0.252 & 0.095 & -0.018 & 0.111 & -0.159 & 0.094 \\
\hline Surgery & -0.198 & 0.084 & -0.123 & 0.094 & -1.134 & 0.098 & -0.405 & 0.085 \\
\hline R-squared & 0.649 & & 0.681 & & 0.389 & & 0.634 & \\
\hline No. of observations & 2651 & & 2079 & & 2651 & & 2638 & \\
\hline
\end{tabular}


Table 3 Rank Correlations and Regression Results (Concentration)

\begin{tabular}{l|cc|cc|cc}
\hline & \multicolumn{2}{|c|}{ Prices } & \multicolumn{2}{c|}{ Citations } & \multicolumn{2}{c}{ No. journals } \\
\cline { 2 - 7 } & Coeff. & St. Err. & Coeff. & St. Err. & Coeff. & St. Err. \\
\hline & & & & & & \\
Spearman Rank Correlations & & & & & & \\
Correlation Coefficient and t-value (C1) & 0.548 & 2.930 & 0.619 & 3.520 & 0.535 & 2.830 \\
Correlation Coefficient and t-value (C2) & 0.581 & 3.190 & 0.677 & 4.110 & 0.513 & 2.670 \\
& & & & & & \\
For profit dummy (FP) & 1.996 & 0.164 & 1.782 & 0.163 & 1.712 & 0.103 \\
FP for NFP account (NFPP) & 1.015 & 0.211 & 0.988 & 0.208 & 0.723 & 0.209 \\
No. of citations & 0.037 & 0.021 & 0.072 & 0.021 & 0.063 & 0.020 \\
No. of citations*FP & 0.119 & 0.027 & 0.110 & 0.026 & 0.112 & 0.027 \\
No. of citations*NFPP & 0.026 & 0.032 & 0.025 & 0.031 & 0.009 & 0.031 \\
Age & -0.217 & 0.038 & -0.222 & 0.038 & -0.225 & 0.037 \\
Age*FP & 0.333 & 0.050 & 0.319 & 0.049 & 0.310 & 0.049 \\
Age*NFPP & 0.170 & 0.059 & 0.163 & 0.059 & 0.165 & 0.058 \\
No. of articles & 0.562 & 0.026 & 0.483 & 0.027 & 0.494 & 0.026 \\
No. of articles*FP & -0.152 & 0.035 & -0.107 & 0.035 & -0.102 & 0.034 \\
No. of articles*NFPP & -0.077 & 0.045 & -0.068 & 0.044 & -0.021 & 0.044 \\
English language dummy & 0.462 & 0.056 & 0.437 & 0.055 & 0.416 & 0.055 \\
Intercept & 1.429 & 0.166 & 1.780 & 0.141 & 1.642 & 0.142 \\
& & & & & & \\
Concentration (C1) & 0.377 & 0.035 & 0.407 & 0.031 & 0.498 & 0.034 \\
Concentration (C1)*NFP & & & -0.067 & 0.008 & -0.079 & 0.015 \\
& & & & & & \\
R-squared & 0.582 & & 0.593 & & 0.597 & \\
No. of observations & 2651 & & 2651 & & 2651 & \\
& & & & & &
\end{tabular}

